\title{
Exfoliation forces of cultured kelp (Laminaria japonica) from the braided rope out of gill-net
}

\author{
NARIHARU YAMASHITA, ${ }^{1}$ TOMONORI KANEDA ${ }^{2}$ TAKESHI HAMADA ${ }^{3}$ TAKAYOSHI MIKAMI, \\ SHUNI JANUMA, ${ }^{1}$ AND KATSUAKI NASHIMOTO ${ }^{1}$ \\ ${ }^{I}$ Graduate School of Fisheries Sciences, Hokkaido Univ., Minato, Hakodate, Hokkaido 041-8611, Japan \\ (seiji@fish.hokudai.ac.jp), ${ }^{2}$ Hokkaido Central Fisheries Experimental Station, Yoichi 046-8555, Hokkaido, and \\ ${ }_{3}^{3}$ Institute of Fisheries Management Technology, 107-0052, Tokyo, Japan.
}

SUMMARY : To reuse the garbage fishing gears effectively to the other fisheries production means is the one of rational measures based on the zero-emission concept. This research has aimed to check the ability of regenerated rope with refused gill-net from amiylane material to kelp cultivation facilities.

By the results of some field tests and stochastic analysis, a large individual kelp grew more abundantly on the regenerated rope of gill-net(GR) than the polyethylene rope(PR), which is widely used for cultivation in Japan. The average force to detach kelp from GR comes up to $6.8 \mathrm{~kg}$ in comparison with the case of PR by $4.6 \mathrm{~kg}$. Through the tensile test in a site, the exfoliation probabilities in typical three portions on a kelp have showed the sticking capacity onto GR surpassed PR. Also, kelp on GR has not been easily broken out from a cultivation rope rather than PR.

\section{KEY WORDS : exfoliation, kelp farming, gill net, recycle, breaking force}

\section{INTRODUCTION}

Thirteen species of kelp has been produced in Japan, and the main production area is limited in the northern part. The average production of kelp has kept on 25 thousand tonnage in a year which is equal to 31 billion yen since ten years ago, so that this fishery is the one of most important fishery. MA-KONBU in Japanese, Laminaria japonica, can be produced only in Hokkaido region. Its unit price reaches close to 8,000 yen per $\mathrm{kg}$, contrastively the others species being extent of only 1,000 or 2,000 yen. This fishery has very unique feature against the other domestic fisheries which can be seen broadly so that the artificial kelp farming with hanging method has occupied up to $20 \%$ in the whole production of kelp, particularly in MA-KONBU farming. A seed of kelp is normally planted into a cultivation rope with $20 \mathrm{~mm}$ in diameter in October. Well cultivated kelp reached over 5 meter in length can be harvested from the next July to September, within only one year cycle.

The kelp cultivation technique is fully developed, but some problems have been still remained in the facilities which always face with rough water condition. One of the issues is how to determine the adequate substrata and structure to larval kelp or algae, which were reported in some articles. ${ }^{1-6)}$ The others $^{7-10)}$ are related to recapture kelp moved away from the substrata of cultivation or natural reefs.

By the way, the domestic production of chemical fishing gears would be estimated not less than one thousand tonnage in a year. Although some researchers in fisheries engineering have recommended to reuse the wasted gear and chemical products to the artificial reefs in their articles, ${ }^{11-12)}$ the used chemical gears have been not so well treated till recently, because the cost coming up.

This study was attempted to check whether the regenerated rope could be applied to a cultivation rope as the appropriate material, which was made out of a refused gill net with certain porosity. If the availability of the reuse could be confirmed, we can get more benefit from not only the well-grown kelp products but also the reduction of recycle cost.

\section{MATERIALS AND METHODS}

\section{Settlement of sample}

The cotyledon of kelp yielded in Siriuchi reagion faced to the Tsugaru Straits had been planted every 30 $\mathrm{cm}$ interval into the regenerated rope(GR) which made out of used gill net with multi-filament (amylane) at $28^{\text {th }}$ on Nov. in' 90 . At the same time, the polyethylene rope (PR) for the control had been treated with same 
way, which is widely used for cultivation in Japan. The diameter of GR was $20 \mathrm{~mm}$ as same as the PR. The unit length of each cultivation rope was $15 \mathrm{~m}$. Both these ropes were brought to the test field Suttu shown in Fig.1.

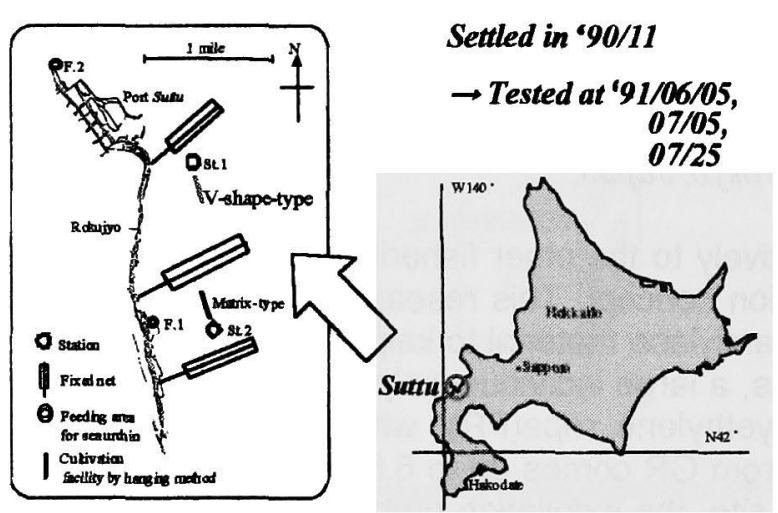

Fig.1 Location of test field

The kelp in each rope were settled into the two sets of the V shaped facility which is drawn in Fig.2. Both end of the cultivation rope has the detachable $C$ clumps. The structure of this cultivation facility has been well developed to stand up to rough water and also widely used for kelp farming in Japan sea area, particularly. The main rope which had $200 \mathrm{~m}$ total length hanged 15 sets of the unit cultivation rope from itself. The depth to bring up kelp ranged within from 3.0 to 5.0 meter. These ropes for field examination could be exposed to the same sea condition as possible during nursery.

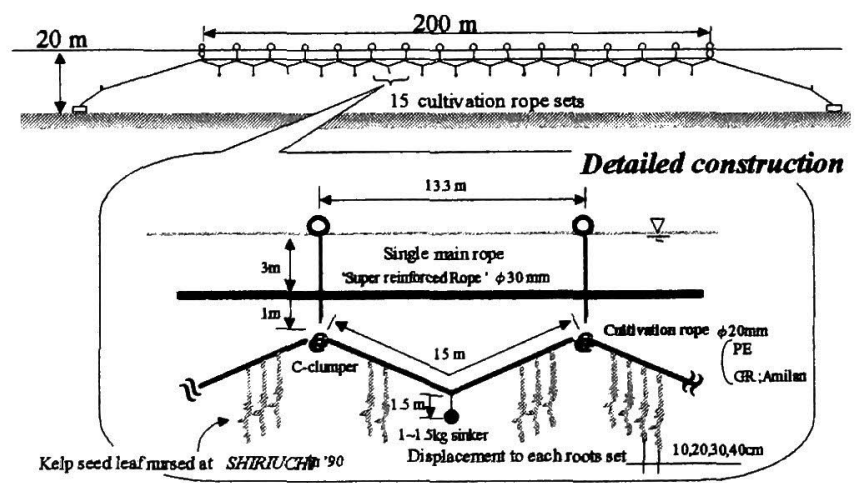

Fig.2 Schematic layout of the V shaped facillity

\section{Measurements}

The field test had done three times in the next Jun. $5^{\text {th }}$ and in the Jul. $5^{\text {th }}$ and $25^{\text {th }}$. Well-grown kelp were landed as exactly same condition as it was just hauled up in the cultivation field for the tests. The samples were maintained on the cultivation rope put into sea near by the wharf during the tests. Without harming the root block of kelp, the sample leaf for tensile test was chosen randomly from the one block on the test plate as shown in Fig.3.

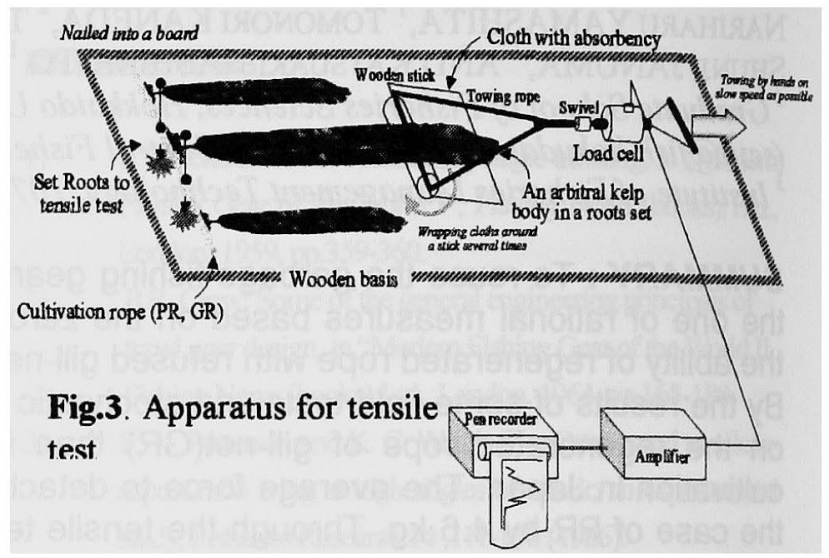

The segment of a cultivation rope without roots of kelp was nailed on the wooden board as the figure.

After the total length and width were measured at first, the test sample was put along elongation distance.

For tensile test, leaf on the other end of the nailed rope was wound tightly around a wooden stick.

While the end side of sample was pulled with no impact as possible as the operator can do, the broken force or pull down force of kelp from a cultivation rope was acquired by the pen recorder which connected to the amplifier through the electric load cell (full capacity is $10 \mathrm{kgf}$ ). Although the broken portion to each rope was recorded simultaneously, the typical portion of kelp had been already categorized to Blade as the part of leaf and Stipe as the stem and Holdfast as the part of roots, which are shown in Fig.4.

These tests carried out over thirty individual samples which selected from the independent set of roots.

The result of growth and the exfoliation force in each broken portion

determined the performance of preventing exfoliation of kelp from the rope. The other advanced

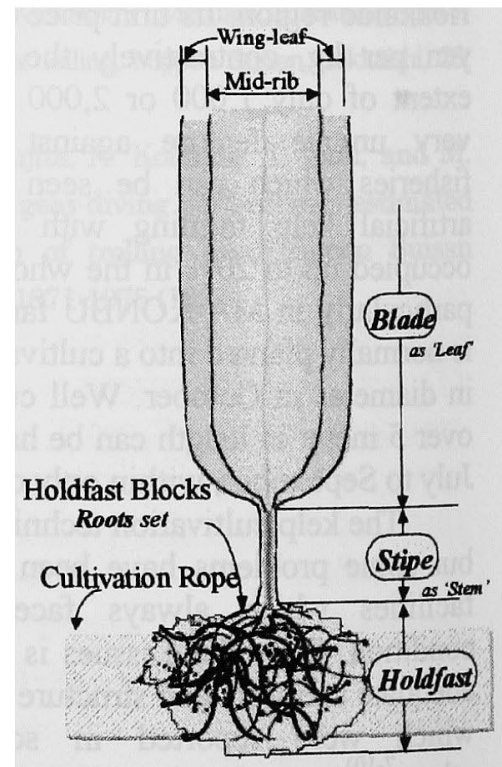

Fig.4 Categorized portion 
theoretical analysis concerned with the exfoliation probability also was investigated.

\section{RESULTS}

\section{Growth condition}

41 samples of PR and 38 samples of GR were examined. Fig.5 shows the distribution of total length of the samples. The averaged weight of one set of roots was $5.05 \mathrm{~kg}(\mathrm{no} .41)$ and $5.09 \mathrm{~kg}$ in GR and PR, respectively. There is no significant difference to the weight and the length of developed kelp on each rope. But, GR seemed to promote the growth of larger kelp than PE.

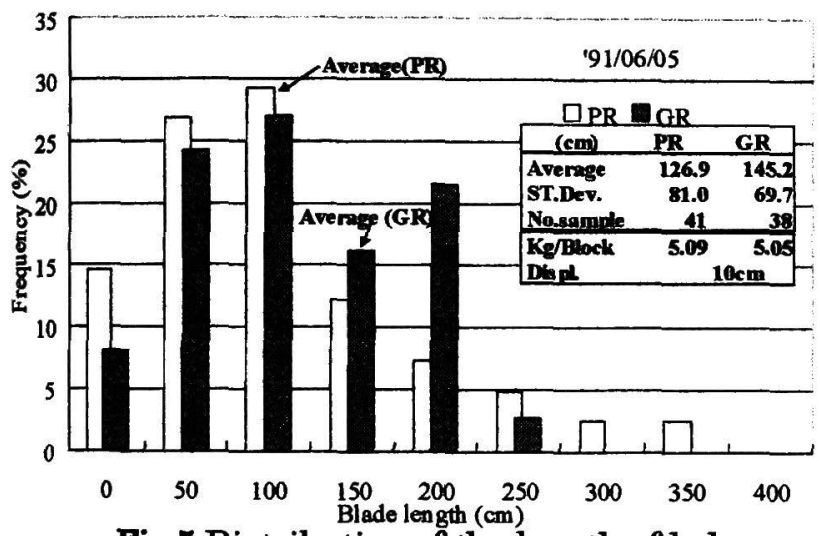

Fig.5 Distribution of the length of kelp

\section{Exfoliation force}

Fig.6 shows the whole results condensed in one. By the graph, the transition trend of date to adhesive force can be compared. Also, the difference of tensile strength among the portions of kelp and the material of ropes can be considerable.

The average exfoliation force, which was actually measured in a site, was $5.0 \mathrm{~kg}$ in the case of PE and $7.5 \mathrm{~kg}$ in the GR at Jun. $5^{\text {th }}$. On the case of Jul. $5^{\text {th }}$, the force showed $5.7 \mathrm{~kg}$ and $7.9 \mathrm{~kg}$, respectively. The average exfoliation force of GR had taken bigger values than PE regardless of the date.

\section{Broken portion and force}

The observed frequency of breaking in the case of GR turned to Stipe, Holdfast and Blade in ascending order. Contrastingly, the case of PR turned to Blade, Stipe and Holdfast.

The calculated frequency and force of the exfoliation, which was conduced from the broken chain model are shown in Fig.6. By the results, the average strength of the exfoliation comes to $6.8 \mathrm{~kg}$ of GR and $4.6 \mathrm{~kg}$ of PR. The exfoliation probability was decided to $47 \%$ in GR and $56 \%$ in PR.

Finally, it is sure that the adhesive capacity of kelp in the regenerated rope has exceeded in the polyethylene rope which is widely used in a site, under $90 \%$ significant difference.

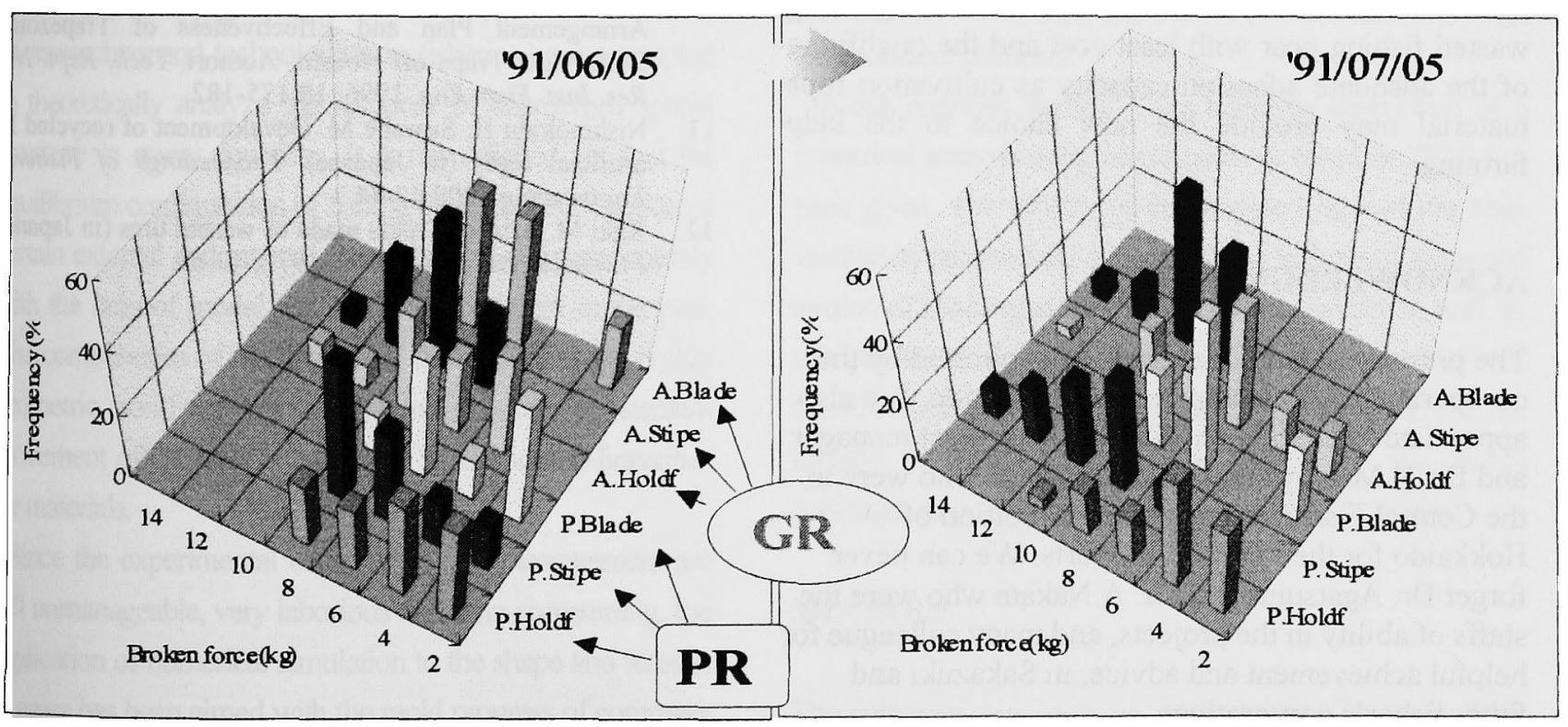

Fig.6 Exfoliation force (Broken force) of each portion to the material of rope 


\section{DISCUSSION AND CONCLUSION}

The regenerated rope which is made out of the multi filament gill net has enough porous space comparatively to the polyethylene rope. This different property of material may become to the one reason of that the harvested kelp on GR comparatively develop larger than PE

By the other way, the other tensile test revealed that the breaking stress of kelp on each rope was not different under stochastic meanings. In this test, the formed piece of kelp like as to metal material were applied.

There is no difference with the tensile stress of kelp on each rope. Only the size of kelp is different. The kelp on GR seems to be growing more strongly than the normal rope. The adhesive strength of roots is exceeding the other portions, also. Furthermore, the results of growth and this stochastic analysis insists that the kelp on the regenerated rope has higher tolerance to the exfoliation rather than the polyethylene rope.

However, it is almost true that the rope made of polyethylene was the best materials to avoid destroying the facilities by rough sea on the developing facilities. Although the most adaptable materials would have to be designed and applied to the facilities of farming, the historical necessity might allow PR continuously to be used.

But, by the view point of zero-emission, we can conclude as follows. Although the reason why GR promote to develop the growth of kelp is one of the issues in the future research, the merit of reusing wasted fishing gear with least cost and the qualifying of the adequate adhesion capacity as cultivation rope material may provide the new choice to the kelp farming.

\section{ACKNOWLEDGMENTS}

The present research was partially supported by the co-operative scholarship grant of Hokkaido. We also appreciate to Dr. S.Nishikawa as the project manager and Dr. K.Matsuyama as the conductor who were in the Central Fisheries Experimental Station of Hokkaido for their special supports. We can never forget Dr. Agatsuma and Dr. A.Nakata who were the staffs of ability in the projects, and many colleague for helpful achievement and advice, in Sakazuki and Suttu fisher's corporations.

\section{REFERENCES}

1. Taniguchi $\mathrm{K}$, Yamane $\mathrm{H}$, Sasaki $\mathrm{K}$, Agatsuma $\mathrm{Y}$, Arakawa H. Marine Afforestation of the Kelp Eisenia bicyclis in Coralline Flats by Introduction of Porous-Concrete Reefs. Nippon Suisan Gakkaishi 2001; 67:858-865.

2. Arakawa $\mathrm{H}$, Okada $\mathrm{R}$, Okabe $\mathrm{H}$, Morinaga $\mathrm{T}$, Taniguchi $\mathrm{K}$. Uniaxial compression strength and erosive potential rate of rocks in strata on the coast of Miura Peninsula with specific relation to the algal communities of Eisenia bicyclis and Ecklonia cava. Fisheries Science 2000; 66:473-480.

3. Kaneda $T$, Kuwahara $K$. The adhesive mechanism of the spore Laminaria religiosa under uniform flow (in Japanese). Proceedings of Fisheries Engineering 2000;77-78.

4. Arakawa H, Morinaga T. The Rate of Brown Algal Zoospores Adhered in the Seaweed Substrate in Relation to Gradient fo the Substrate. Nippon Suisan Gakkaishi $1994 ; 60: 461-466$.

5. Floreto $E$, Teshima S, Ishikawa $M$. The Effects of Seaweed Diets on the Growth, Lipid and Fatty Acids of Juveniles of the White Sea Urchin Tripneusgtes gratilla. Fisheries Science 1996; 62:589-593.

6. Gerard V. Hydrodynamic streamlining of Laminaria saccharina LAMOUR. in response to mechanical stress. J.Exp. Mar. Biol. Ecol. 1987; 107:237-244.

7. Kawamata S. Adaptive Development of Tolerance to Wave-Induced Dislodgement for Cultured Laminaria japonica in Response to Water Movement. Nippon Suisan Gakkaishi 2000; 66:651-657.

8. Kawamata S, Sasaki R. Field Performance of Framed Structures for Preventing Flow-Induced Loss of Food Algae in Abalone and Sea urchin Aquaculture. Fisheries Engineering 1999; 36:175-182.

9. Kawamata S, Isogami K. Functional Limit of Block-type Drift-algal Traps under Waves. Fisheries Engineering 1999; 36:11-19.

10. Kawamata S, Uemura $\mathrm{Y}$. Field Investigations on Arrangement Plan and Effectiveness of Trapezoidal Drift-Algal Traps off Noushi, Aomori. Tech. Rept. Nat. Res. Inst. Fish. Eng. 1996; 18:175-182.

11. Nishinokubi H, Suwabe M. Development of recycled PE artificial reefs (in Japanse). Proceedings of Fisheries Engineering 2000;43-44.

12. Kaki M. Artificial reefs made of wasted tires (in Japanse). Fisheries civil engineering 1972; 49-60. 